\title{
Correlation between fecal calprotectin levels, disease severity and the hypervirulent ribotype 027 strain in patients with Clostridium difficile infection
}

\author{
Avi Peretz ${ }^{1,2^{*}}$, Linda Tkhawkho ${ }^{1}$, Nina Pastukh', Diana Brodsky ${ }^{1}$, Chen Namimi Halevi ${ }^{3}$ and Orna Nitzan ${ }^{2,4}$
}

\begin{abstract}
Background: Clostridium difficile is the most common infectious etiology of nosocomial diarrhea. Fecal calprotectin $(\mathrm{fc})$ is a sensitive marker of intestinal inflammation, found to be associated with enteric bacterial infections and inflammatory bowel disease.

Methods: We evaluated fc levels using a Chemiluminescent immunoassay method, in hospitalized patients with C. difficile infection (CDI) diagnosed by molecular stool examination and assessed correlation with virulent ribotype 027 strain infection, antibiotic susceptibility by gradient Etest strip performed on C. difficile colonies and clinical and laboratory measures of disease severity. Statistical analysis was performed for correlation of fc levels with clinical and laboratory parameters, disease severity and patient outcomes.

Results: Overall 29 patients with CDI were admitted at the Poria medical center in northern Israel, during June 2014-May 2015. Resistance to metronidazole was found in $3(10.3 \%)$ isolates and to vancomycin in $5(17.2 \%)$ isolates. Regarding patient outcomes, within 30 days of CDI diagnosis, recurrence of disease occurred in 10 (34.5\%) patients and 2 patients (6.9\%) died. Seven (24.1\%) isolates were C. difficile ribotype 027. Mean fc level was $331.4 \mu \mathrm{g} / \mathrm{g}$ (21-932). Higher fc levels were found in patients with C. difficile ribotype $027(p<0.0005)$. Fc levels were also correlated with elevated peripheral blood white cell count $(p=0.0007)$. A trend for higher $f c$ levels was found in patients with a higher clostridium severity score index $(p=0.0633)$. No correlation was found between fecal calprotectin levels and age, sex, functional status, community versus hospital acquired CDI, antibiotic susceptibility, fever, and creatinine levels.
\end{abstract}

Conclusions: Our study highlights the fact that $\mathrm{fc}$ has a potential role as a biomarker of disease severity and binary toxin producing ribotype associated disease.

Keywords: Calprotectin, Clostridium difficile, Ribotype 027, Clostridium severity score index

\section{Background}

Clostridium difficile (C. difficile) is the most common infectious etiology of nosocomial diarrhea in acute care settings, accounting for $15-25 \%$ of all cases of antibioticinduced diarrhea. C. difficile infection (CDI) is caused by toxigenic $C$. difficile that usually produces 2 major toxins - toxin A, an enterotoxin, and toxin B, a potent

\footnotetext{
* Correspondence: aperetz@poria.health.gov.il

${ }^{1}$ Clinical Microbiology Laboratory, Baruch Padeh Medical Center, Poria, Tiberias, Israel

${ }^{2}$ Faculty of Medicine, Bar Ilan University, Galilee, Israel

Full list of author information is available at the end of the article
}

cytotoxin [1-3]. The emergence of a hyper-virulent clone of $C$. difficile, ribotype 027, in North America and Europe in the 2000s has caused numerous outbreaks in the healthcare setting [4]. Most patients develop diarrhea during or shortly after starting antibiotics. However, 25-40\% of patients may not become symptomatic for as long as 10 weeks after completing antibiotic therapy. Symptoms range from mild watery diarrhea and cramping abdominal pain, to fulminant colonic infection with complications of toxic megacolon, perforation and death. Several scoring systems that predict disease prognosis and aid in treatment decisions have been developed, including 
the clostridium severity score index that incorporates 9 clinical and laboratory variables. Antibiotic treatment of CDI consists of metronidazole in mild cases and vancomycin in moderate to severe infection, although treatment failures and recurrence of disease occur often [5, 6]. Fecal calprotectin (fc) is a sensitive marker of intestinal inflammation, and was found to be associated with enteric bacterial infections and inflammatory bowel disease [7]. Calprotectin is a $24 \mathrm{kDa}$ dimer of calcium binding proteins S100A8 and S100A9. The complex accounts for up to $60 \%$ of the soluble protein content of the neutrophil cytosol. In vitro studies show that calprotectin has bacteriostatic and fungistatic properties that arise from its ability to sequester manganese and zinc $[8,9]$.

The aim of our study was to evaluate fc levels in hospitalized patients with CDI and to assess if fc levels are correlated with ribotype 027 strain infection, with reduced susceptibility of the infectious strain to metronidazole or vancomycin, with clinical and laboratory tools of disease severity, as calculated by the Clostridium severity score index.

\section{Results}

Out of 29 patients with CDI, 15 were females and 14 were males. Mean age was 64.5 years (17-95). Fifteen patients $(51.7 \%)$ were functionally debilitated and 5 (17.2\%) were nursing home residents. Thirteen patients (44.8\%) were community acquired cases and 16 patients (55.2\%) represented nosocomial CDI. In 24 cases the Clostridium severity score index was $\leq 3$, and a score of 4-6 points was calculated in 5 patients. Reduced susceptibility to metronidazole was found in $3(10.3 \%)$ isolates and to vancomycin in $5(17.2 \%)$ isolates. Regarding patient outcomes, within 30 days of CDI diagnosis, recurrence of disease occurred in $10(34.5 \%)$ patients, and 2 patients (6.9\%) had died. One patient (3.4\%) developed a toxic megacolon. Seven $(24.1 \%)$ isolates were identified as C. difficile ribotype 027 . Among the 13 community acquired patients with CDI, only 2 had the 027 ribotype, and among the 16 nosocomial cases, 5 were 027 ribotype positive. The mean severity score for ribotype 027 patients was 2.86 versus 1.95 in ribotype 027 negative patients.

Mean calprotectin level was 331.4 $\mu \mathrm{g} / \mathrm{g}(21-932)$. We performed assessment of the correlation between fecal calprotectin levels and clinical and laboratory parameters. We found higher calprotectin levels in patients with $C$. difficile ribotype 027, with a mean level of $811.9 \mu \mathrm{g} / \mathrm{g}$ (659-932), compared to patients with other $C$. difficile ribotypes, with a mean level of $178.6 \mu \mathrm{g} / \mathrm{g}(21-522), p<0.0005$ (Fig. 1). A significantly positive correlation of calprotectin levels was found with elevated peripheral blood white cell count $(p=0.0007)$. A trend for higher calprotectin levels was found in patients with a higher clostridium severity score index $(p=0.0633)$. No correlation was found between fecal calprotectin levels and age, sex, functional status, community versus nosocomial acquired CDI, antibiotic susceptibility, fever, and creatinine levels (Table 1). No correlation was found between $\mathrm{fc}$ levels and disease recurrence or mortality at 30 days, with a mean level of $284.7 \mu \mathrm{g} / \mathrm{g}$ (46-840) versus $356.1 \mu \mathrm{g} / \mathrm{g}$ (21-932) in those with and without recurrence, and $579.5 \mu \mathrm{g} / \mathrm{g}(248-911)$ versus $313.1 \mu \mathrm{g} / \mathrm{g}(21-932)$ in the patients who died versus those that survived ( $p=0.6662$ and $p=0.255$, respectively.).

\section{Discussion}

C. difficile is the leading infectious cause of antibioticassociated diarrhea. CDI symptoms range from mild watery

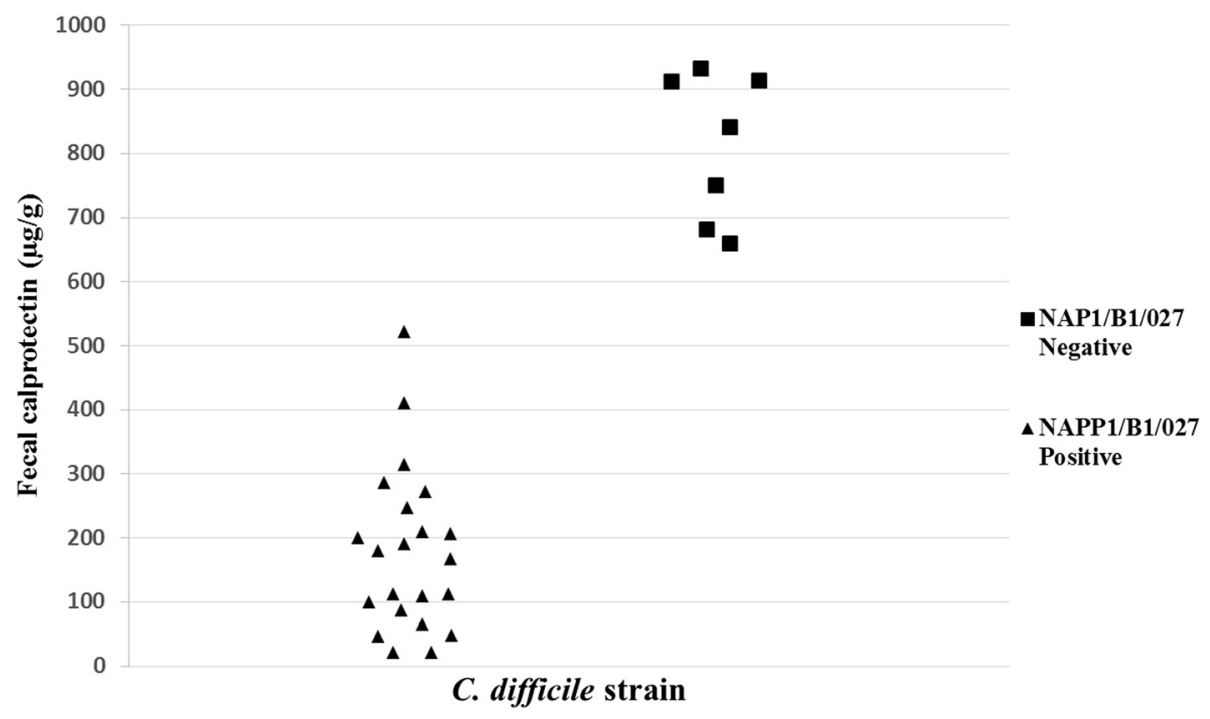

Fig. 1 Fecal Calprotectin levels in patients with Clostridium difficile infection. and correlation with fecal Calprotectin levels 
Table 1 Clinical and laboratory parameters of patients with Clostridium difficile infection and correlation with fecal Calprotectin levels

\begin{tabular}{|c|c|c|c|}
\hline Parameter & $\begin{array}{l}\text { Mean } \\
\text { (percent/range) }\end{array}$ & $\begin{array}{l}\text { fc levels }(\mu \mathrm{g} / \mathrm{g}) \text {, } \\
\text { mean (range) }\end{array}$ & $\begin{array}{l}P \text {-value for correlation } \\
\text { with fc levels }\end{array}$ \\
\hline \multicolumn{4}{|l|}{ Antibiotic-reduced susceptibility } \\
\hline \multirow[t]{2}{*}{ Metronidazole } & $3(10.3 \%)$ & $\begin{array}{l}\text { Reduced susceptibility to Metronidazole: } \\
177.7(46-287)\end{array}$ & 0.5474 \\
\hline & & Metronidazole susceptible 349 (21-932) & \\
\hline \multirow[t]{2}{*}{ Vancomycin } & $5(17.2 \%)$ & $\begin{array}{l}\text { Reduced susceptibility to Vancomycin } \\
336.8 \text { (113-932) }\end{array}$ & 0.7316 \\
\hline & & Vancomycin susceptible 330.3 (21-912) & \\
\hline \multicolumn{4}{|l|}{ Gender } \\
\hline Male & $15(51.7 \%)$ & $340.8(48-932)$ & \\
\hline Female & $14(48.3 \%)$ & $321.4(21-911)$ & 0.7622 \\
\hline Age (years) & $64.5(17-95)$ & & 0.2764 \\
\hline \multicolumn{4}{|l|}{ Functional status } \\
\hline Independent & $14(48.3 \%)$ & $316.8(21-932)$ & \\
\hline Debilitated & $15(51.7 \%)$ & $45.1(46-911)$ & 0.6815 \\
\hline \multicolumn{4}{|l|}{ CDI acquisition } \\
\hline Community & $10(34.5 \%)$ & $273.6(21-911)$ & \\
\hline Nursing home & $3(10.3 \%)$ & $234.7(21-411)$ & \\
\hline Hospital & $16(55.2 \%)$ & $385.8(46-932)$ & 0.5678 \\
\hline Body temperature $\left({ }^{\circ} \mathrm{C}\right)$ & $37.0(36-39.4)$ & & 0.8772 \\
\hline Peripheral white blood cell count $(/ \mu \mathrm{l})$ & $13,363(3070-43,210)$ & & 0.0007 \\
\hline Creatinine(g/dL) & $1.3(0.2-6.7)$ & & 0.2 \\
\hline \multirow[t]{2}{*}{ Disease recurrence in 30 days } & $10(34.5 \%)$ & Disease recurrence 284.7 (46-800) & 0.6662 \\
\hline & & No recurrence 356.1 (21-932) & \\
\hline \multicolumn{4}{|l|}{30 day mortality } \\
\hline Yes & $2(6.9 \%)$ & $579.5(248-911)$ & \\
\hline No & $27(93.1 \%)$ & $313.3(21-932)$ & 0.2550 \\
\hline Clostridium severity score index & $2.17(1-6)$ & & 0.0633 \\
\hline
\end{tabular}

diarrhea to severe colitis, toxic megacolon, colonic perforation, and death. Guidelines for treatment of CDI stratify antibiotic treatment according to disease severity [6]. Currently there are several scoring systems, these consist of non-specific clinical and laboratory parameters that, as a whole, estimate disease severity and patient prognosis [10-12]. The search for specific markers indicative of disease severity is of great importance. As an example, in one study it was found that elevated PCT levels are associated with the severe CDI [13].

Recently, a few studies found that fecal calprotectin levels are associated with acute bacterial gastroenteritis $[14,15]$, despite the fact that up to now fc was used only to stratify between inflammatory and non-inflammatory bowel diseases. Calprotectin is a $24 \mathrm{kDa}$ dimer of calcium binding proteins that accounts for up to $60 \%$ of the soluble protein content of the neutrophil cytosol. Several recent studies found that fc levels are elevated in patients with CDI, compared with patients with non- $C$. difficile antibiotic-associated diarrhea and with patients with $C$. difficile colonization only $[16,17]$. In this study we aimed to find if fc levels are correlated with CDI severity and with disease caused by ribotype 027; this specific strain is associated with higher morbidity and mortality rates and increased antibiotic resistance. We found that fc levels were significantly associated with $C$. difficile ribotype 027 . In routine practice most microbiology laboratories do not regularly assess $C$. difficile ribotype because the diagnosis is based on ELISA toxin assays, which don't identify ribotypes. However, the elevated fc levels might alert clinicians to the possibility of a more severe and complicated course of disease that is associated with this ribotype. This may also affect empiric choice of the antibiotic therapy. For example, fidaxomicin treatment decreases recurrence rates in CDI, but not in cases of ribotype 027 associated disease [18]. Another study of 164 patients with CDI found a nonsignificant correlation of fc levels and ribotype 027 [16]. 
This might be due to analysis of fc levels in 4-tier percentile categories and not as a linear value as done in our study. We also found fc levels to be significantly associated with a higher peripheral blood white cell count, which might reflect an elevated degree of intestinal inflammation that is associated with fc stool levels. In this study there was a trend towards higher fc levels in patients with more severe disease as assessed by the clostridium severity score index. Statistical significance may not have been achieved due to the relatively small sample size. One other study assessed the correlation between disease severity and fc levels and found a non-significant higher mean stool fc level in patients with severe disease, although in this study a different severity scoring system was used [16].

The main limitation of our study was the small sample size, reflecting the fact that our medical center is a 300 bed hospital serving only the North-East of Israel and thus we do not have many patients with community acquired $\mathrm{CDI}$, and due to rigorous infection control programs we do not have many cases of nosocomial CDI as well. The patients in this paper represent all patients with CDI at our hospital during one year. A larger sample size might have helped us find a stronger correlation between fc levels and disease severity and outcomes.

\section{Conclusions}

Finding novel and easy performance tools for the assessment of CDI severity is an important and crucial goal. Our study highlights the fact that fc has a potential role as a biomarker of the disease severity and binary toxin producing ribotype-associated disease.

\section{Methods}

\section{Patients}

Overall, 29 patients with diarrhea, who were found positive for C. difficile from June 2014 to May 2015, were admitted at the Poria Medical Center located in northern Israel. Identification of $C$. difficile from patients' stool specimens was carried out on a bio-molecular platform, which also enables identification of $C$. difficile ribotype 027 (Xpert ${ }^{\circ}$ C. difficile, Cepheid, Sweden) [19]. The following demographic and clinical data concerning patients with CDI were collected from electronic files: age, sex, functional status, community versus nosocomial acquired CDI, and antibiotic susceptibility.

A clostridium severity score index was calculated. For each patient the score incorporated nine parameters, each variable added one point: altered mental status, abdominal pain or distention, $1500>\mathrm{WBC}>20,000$, ALB $<2.5$, ascites or colitis (imaging), MAP $<65$, pulse $>110$, ICU transfer. A score of 0-3 criteria meant mild disease, 4-6: moderate disease, $\geq 7$ : severe disease [10].
The study protocol was reviewed and approved by the Poria-Baruch Padeh Medical Centre Institutional Review Board/Ethics Committee. A waiver was ushered for informed patient consent.

\section{Fecal calprotectin test}

Calprotectin levels in stool were examined by Liaison ${ }^{\circ}$ Calprotectin Stool (Saluggia, Italy) kit using Chemiluminescent immunoassay (CLIA).

\section{Bacterial culture and determination of in vitro susceptibility}

Antibiotic susceptibility test was performed by culture method of the stool sample on chromID ${ }^{\mathrm{rm}} C$. difficile (bioMérieux, Durham, NC) growth medium and then incubated at $37^{\circ} \mathrm{C}$ in anaerobic conditions for $18-12$ h. C. difficile colonies appear as asymmetric and black-colored colonies [20]. One isolated $C$. difficile colony from the culture was suspended in Thioglycollate broth (Becton Dickinson, Heidelberg, Germany (until density of 1.0 McFarland was reached. The inoculum was spread by cotton swab on Brucella Blood Agar growth medium, supplemented with haemin and vitamin K (Becton Dickinson, Heidelberg, Germany (. MIC determination for metronidazole and vancomycin was performed by a gradient Etest strip (bioMérieux, Durham, NC). Further, antibiotic susceptibility plates were incubated in anaerobic conditions at $37{ }^{\circ} \mathrm{C}$ for $24 \mathrm{~h}$. The interpretation of susceptibility test results was performed in accordance with European Committee on Antimicrobial Susceptibility Testing (EUCAST) recommendations. Based on these recommendations, $C$. difficile isolates are considered as strains with reduced susceptibility values to metronidazole or vancomycin when MIC level $>2 \mathrm{mg} / \mathrm{L}$ [21].

\section{Statistical analysis}

Chi-square test was applied for analyzing the differences in categorical parameters by NAP-1. The Non-parametric Wilcoxon-Mann-Whitney Rank sum was applied for analyzing the difference in the quantitative parameters by NAP-1, and for analyzing differences in calprotectin levels between categorical variables (recurrence, reduced antibiotic susceptibility, death, gender, nursing house, function, and confusion). Pearson correlation was used for testing the association between calprotectin and quantitative parameters for testing the association between calprotectin and categorical parameters. Analysis of Covariance (ANCOVA) model was applied for analyzing the different calprotectin levels by NAP-1 with adjustment to confusion, index-1, and age. All tests applied were two-tailed, and a $p$ value of $5 \%$ or less was considered statistically significant. The data was analyzed using $\mathrm{SAS}^{\oplus}$ version 9.3 (SAS Institute, Cary, North Carolina). 


\section{Abbreviations}

$\mathrm{CDI}$, Clostridium difficile infection; Fc, fecal calprotectin

\section{Funding}

No funding was obtained for this study.

\section{Authors' contributions}

All authors have read and approve of the final version of the manuscript. AP conceived of the study, and participated in its design and coordination and helped to draft the manuscript and aided in the microbiological lab work of stool culture, antibiotic susceptibility and immunoassays. LT participated in culturing the stool and performing immunoassays. NP participated in the molecular biology assays. DB participated in stool culture and molecular biology. CNH participated in the microbiology lab work and in analysis of results, and drafting of paper. ON participated in the design and coordination and helped to draft the manuscript.

\section{Competing interest}

There are no competing financial interests.

\section{Consent for publication}

Not applicable.

\section{Ethics approval and consent to participate}

The study protocol was reviewed and approved by the Poria-Baruch Padeh Medical Centre Institutional Review Board/Ethics Committee. The committee ushered a waiver from informed consent from the patients, due to the fact that for our study we used the same stool sample that was routinely sent for clostridium, and did not obtain another stool sample. Also, the stool tests performed in our study did not in any way affect patient treatment. The ethics committee approval number is: POR15-0057.

\section{Author details}

${ }^{1}$ Clinical Microbiology Laboratory, Baruch Padeh Medical Center, Poria, Tiberias, Israel. ${ }^{2}$ Faculty of Medicine, Bar Ilan University, Galilee, Israel. ${ }^{3}$ The Ruth and Bruce Rappaport Faculty of Medicine, Haifa, Israel. ${ }^{4}$ Unit of Infectious Diseases, Baruch Padeh Medical Center, Poria, Tiberias, Israel.

Received: 12 February 2016 Accepted: 3 June 2016

\section{Published online: 22 June 2016}

\section{References}

1. Lessa FC, Gould CV, McDonald LC. Current status of Clostridium difficile infection epidemiology. Clin Infect Dis. 2012;55 suppl 2:S65-70. doi:10.1093/ cid/cis319.

2. Kelly CP, LaMont JT. Clostridium difficile-more difficult than ever. N Engl J Med. 2008;359(18):1932-40. doi:10.1056/NEJMra0707500.

3. Kuehne SA, Cartman ST, Heap JT, Kelly ML, Cockayne A, Minton NP. The role of toxin $A$ and toxin $B$ in Clostridium difficile infection. Nature. 2010 467(7316):711-3. doi:10.1038/nature09397.

4. He M, Miyajima F, Roberts P, Ellison L, Pickard DJ, Martin MJ, et al. Emergence and global spread of epidemic healthcare-associated Clostridium difficile. Nat Genet. 2013;45(1):109-13. doi:10.1038/ng.2478.

5. Dubberke ER, Han Z, Bobo L, Hink T, Lawrence B, Copper S, et al. Impact of clinical symptoms on interpretation of diagnostic assays for Clostridium difficile infections. J Clin Microbiol. 2011;49(8):2887-93. doi:10.1128/JCM.00891-11.

6. Cohen SH, Gerding DN, Johnson S, Kelly CP, Loo CP, McDonald LC, et al. Clinical practice guidelines for Clostridium difficile infection in adults: 2010 update by the society for healthcare epidemiology of America (SHEA) and the infectious diseases society of America (IDSA). Infect Control Hosp Epidemiol. 2010;31(5):431-55. doi:10.1086/651706.

7. van Rheenen PF, van de Vijver E, Fidler V. Faecal calprotectin for screening of patients with suspected inflammatory bowel disease: diagnostic metaanalysis. BMJ. 2010;341:c3369. doi:10.1136/bmj.c3369.

8. Urban CF, Ermert D, Schmid M, Abu-Abed U, Goodmann C, Nacken W, et al. Neutrophil extracellular traps contain calprotectin, a cytosolic protein complex involved in host defense against Candida albicans. PLoS Pathog. 2009:5(10):e1000639. doi:10.1371/journal.ppat.1000639.

9. Costa F, Mumolo MG, Ceccarelli L, Bellini M, Romano MR, Sterpi C, et al. Calprotectin is a stronger predictive marker of relapse in ulcerative colitis than in Crohn's disease. Gut. 2005;54(3):364-8.
10. Velazquez-Gomez I, Rocha-Rodriguez R, Toro DH, Gutierrez-Nuñez JJ, Gonzalez G, Saavedra S. A severity score index for Clostridium difficile Infection. Infect Dis Clin Pract. 2008;16(6):376-8. doi:10.1097/IPC. Ob013e318182557f

11. Mulherin DW, Hutchison AM, Thomas GJ, Hansen RA, Childress DT. Concordance of the SHEA-IDSA severity classification for Clostridium difficile infection and the ATLAS bedside scoring system in hospitalized adult patients. Infection. 2014;42(6):999-1005. doi:10.1007/s15010-014-0671-8.

12. Public Health England. Updated guidance on the management and treatment of clostridium difficile infection. 2013. http://www.hpa.org.uk/ webc/HPAwebFile/HPAweb_C/1317138914904.

13. Rao K, Walk ST, Micic D, Chenoweth E, Deng L, Galecki AT, et al. Procalcitonin levels associate with severity of Clostridium difficile infection. PLoS One. 2013;8(3):e58265. doi:10.1371/journal.pone.0058265.

14. Shastri YM, Bergis D, Povse N, Schäfer V, Shastri S, Weindel M, et al. Prospective multicenter study evaluating fecal calprotectin in adult acute bacterial diarrhea. Am J Med. 2008;121(12):1099-106. doi:10.1016/j.amjmed. 2008.06.034.

15. Sýkora J, Siala K, Huml M, Varvařovská J, Schwarz J, Pomahačová R. Evaluation of faecal calprotectin as a valuable non-invasive marker in distinguishing gut pathogens in young children with acute gastroenteritis. Acta Paediatr. 2010:99(9):1389-95. doi:10.1111/j.1651-2227.2010.01843.x.

16. Swale A, Miyajima F, Roberts P, Hall A, Little M, Beadsworth MB, et al. Calprotectin and lactoferrin faecal levels in patients with Clostridium difficile infection (CDI): a prospective cohort study. PLoS One. 2014;9(8):e106118. doi:10.1371/journal.pone.0106118.

17. Whitehead SJ, Shipman KE, Cooper M, Ford C, Gama R. Is there any value in measuring faecal calprotectin in Clostridium difficile positive faecal samples? J Med Microbiol. 2014;63(Pt 4):590-3. doi:10.1099/jmm.0.067389-0.

18. Louie TJ, Miller MA, Mullane KM, Weiss K, Lentnek A, Golan Y, et al. OPT-80003 Clinical Study Group. Fidaxomicin versus vancomycin for Clostridium difficile infection. N Engl J Med. 2011;364(5):422-31. doi:10.1056/ NEJMoa0910812.

19. Florea D, Oțelea D, Rafila A, Bădicut I, Popoiu M, Popescue GA. Clinical utility of the GeneXpert assay for the diagnosis of Clostridium difficile infections. BMC Infect Dis. 2014;14 Suppl 7:034. doi:10.1016/j.jhin.2014.03.005.

20. Eckert C, Burghoffer B, Lalande V, Barbut E. Evaluation of the chromogenic agar chromID C. difficile. J Clin Microbiol. 2013;51:1002-4. doi:10.1128/JCM. 02601-12.

21. Adler A, Miller-Roll T, Bradenstein R, Block C, Mendelson B, Parizade M, et al. A national survey of the molecular epidemiology of Clostridium difficile in Israel: the dissemination of the ribotype 027 strain with reduced susceptibility to vancomycin and metronidazole. Diagn Microbiol Infect Dis. 2015:83(1):21-4. doi:10.1016/j.diagmicrobio.2015.05.015.

\section{Submit your next manuscript to BioMed Central and we will help you at every step:}

- We accept pre-submission inquiries

- Our selector tool helps you to find the most relevant journal

- We provide round the clock customer support

- Convenient online submission

- Thorough peer review

- Inclusion in PubMed and all major indexing services

- Maximum visibility for your research

Submit your manuscript at www.biomedcentral.com/submit
C) Biomed Central 